discussion of great apes, emphasizes the importance of female proceptive behaviour as an indicator of female sexual arousal and discusses evidence indicating mating outside the time of ovulation. The debate seems inconclusive, but this is no mere quibble about terminology. Many authors have drawn an artificial distinction between the occurrence of 'oestrus' in simians and the 'loss of oestrus' during human evolution, thereby obscuring a major change during the evolution of simians, rather than specifically during human evolution.

A discussion of conservation is now a standard feature of IPS congresses and the 1990 Kyoto symposium focused on tropical rainforests, with emphasis on the interaction of development and conservation. Sustainability is now in vogue, ferent people (J. Robinson). Studies are reported on traditional use of rainforest by hunter-gatherers (M. Ichikawa) and on shifting cultivation in South-East Asia (K. Tanaka), together with a discussion of 'ethnobiology' in relation to conservation that males may be largely responsible for although it means different things to dif-

(D. Posey). Regrettably, there is a local flavour here, too: logging in South-East Asian insular countries is heavily influenced by a huge Japanese demand for timber. Japan allegedly imports 50 per cent of all-round timber harvested from the world's tropical forests. There is a particular problem with destruction of mangrove swamps in South-East Asia for wood-chip production (Y. Kuroda). Although this makes way for local farming of shrimps (also destined mainly for Japan), the overall cost to fisheries is greater than any commercial gain from felling mangrove forest, as is reported by T. Struhsaker in a survey of five case studies including one in Malaysia. There is, however, an encouraging note in that a new conservation policy of the Japanese government, aimed at promoting sustainability and recycling of paper, was presented to the IPS congress. A readiness for dialogue was also indicated.

R. D. Martin is in the Anthropological Institute and Museum, University of ZürichIrchel, Winterthurerstrasse 190, CH-8057 Zürich, Switzerland.

\section{Memory and molecules}

\section{John Collinge}

Hannah's Heirs: The Quest for the Genetic Origins of Alzheimer's Disease. By Daniel A. Pollen. Oxford University Press: 1993. Pp. 296. \$25, £16.95.

A REVOLUTION is taking place in our understanding of degenerative diseases of the brain. By far the commonest of these is Alzheimer's disease: by the age of $75-80$, 20 per cent of us may be affected by it. "The disease of the century", as Daniel Pollen refers to it, is in a sense born of the success of medicine in increasing the average lifespan of the population, and its treatment or prevention now stands as one of medicine's greatest challenges.

Only in the past two years have definitive causes of Alzheimer's disease been elucidated. Despite the sustained efforts of neuroscientists over several decades, the aetiology remained obscure: the nervous system is extremely complex and it is difficult to interpret whether a particular anatomical or chemical change is related to the underlying cause of the disease or, more likely, represents a sequel to the dramatic and devastating events of the neurodegenerative process.

A few cases of Alzheimer's were known to run in families, and their distribution suggested that an autosomal gene was responsible. Advances in molecular genetics provided a way of locating the gene and determining, albeit perhaps only in a few families initially, a defini- tive cause of the disease. Researchers could then focus activities on a single protein and, from this foundation, it might be possible to unravel the complex mixture of genetic and environmental factors behind the commoner sporadic type of the disease.

In Hannah's Heirs, Pollen, a Boston neurologist with wide experience in this work, describes the search for Alzheimer's genes from the perspective of some of the families afflicted by this devastating illness. His starting point is the story of Hannah's family. In the late $1800 \mathrm{~s}$ in Byelorussia, 40-year-old Hannah began to suffer from progressive memory loss. Years later, one of her descendants turned up at the author's clinic suffering from the same disease; many members of the family had been similarly afflicted over the intervening five generations. The historical and social perspective is compelling - a vivid reminder of the tragedy and horror of an illness that afflicts the very characteristics that define us as human beings. The simple and unending courage of family members should be a source of motivation to all those involved in Alzheimer's research.

Pollen provides a background to the latest discoveries by outlining the fundamental contributions of Mendel, Alzheimer, Morgan, Crick and Watson before comprehensively detailing the remarkable recent advances in our understanding of the human genome. Although fine for those familiar with the terminology, the description of this progress may not be totally comprehensible to the general reader. More explanation would have conveyed this exciting story to an even wider audience: for example, simple diagrams explaining concepts such as linkage, restriction fragment length polymorphism, DNA probes and recombination would have made what is an otherwise very well written book more accessible. Molecular genetics has shifted the approach to the aetiology of diseases not classically regarded as 'genetic'. The public must understand the dramatic nature of such advances if they are to support genome research. I hope that this book will contribute to the communication of such ideas.

The last part of the book deals with the steps leading to the first identification of a defined cause of Alzheimer's, mutations in the amyloid precursor protein (APP) gene, and subsequent advances. A second gene, on chromosome 14, has been located, and is linked to the disease in Hannah's family. A coverage of the importance of apolipoprotein $\mathrm{E}$ brings the story completely up to date.

The evolution of the term 'Alzheimer's disease' is documented throughout the book. Its extension in the 1970 s to encompass what was previously known simply as senile dementia was crucial in attracting public attention and funding. Ironically, the research this success encouraged has now unequivocally demonstrated that Alzheimer's disease has many different causes. It remains to be seen if the causes are eventually all channelled through a common final pathway. If they are, then it may be easier to develop therapies that can be widely applied.

Pollen has done an excellent job in crediting the many workers in all the international research groups involved in the quest. A key lesson is the way in which linkage studies led to the rejection, at least for a while, of the APP gene as a candidate for the disease. One anecdote that does not appear in the book derives from the British practice of putting blue plaques on buildings where historical events occurred or notable people lived. St Mary's Hospital Medical School in London has one to mark where Fleming discovered penicillin, but for a while a plaque also appeared on the door of John Hardy's office. His research group had produced a replica reading: "this was where John Hardy demonstrated that APP was not the gene for Alzheimer's disease". The word 'not' had been crossed out. This book is crammed with human triumphs of both the intellect and the spirit, and deserves a wide readership.

John Collinge is in the Department of Biochemistry, St Mary's Hospital Medical School, Norfolk Place, London W2 1PG, UK. 